\title{
Correction to: Hepatocellular carcinoma diagnosis using a novel electrochemiluminescence immunoassay targeting serum IgM-free
} AIM

\author{
Tomo Shimizu ${ }^{1}$. Takashi Sawada ${ }^{1}$. Tomohide Asai ${ }^{1}$ Yuka Kanetsuki ${ }^{1}$. Jiro Hirota ${ }^{1}$ - Michihisa Moriguchi ${ }^{2}$. \\ Tomoaki Nakajima $^{3} \cdot$ Toru Miyazaki $^{4,5,6,7} \cdot$ Takeshi Okanoue $^{8}$
}

Published online: 4 February 2022

(c) The Author(s) 2022

\section{Correction to: Clinical Journal of Gastroenterology https://doi.org/10.1007/s12328-021-01567-4}

In the original publication of the article, the Supplementary File 2 was published with red fonts. The correct Supplementary File 2 is given in this correction.

The original article has been corrected.
Supplementary Information The online version contains supplementary material available at https://doi.org/10.1007/s12328-022-01601-z.

Open Access This article is licensed under a Creative Commons Attribution 4.0 International License, which permits use, sharing, adaptation, distribution and reproduction in any medium or format, as long as you give appropriate credit to the original author(s) and the source, provide a link to the Creative Commons licence, and indicate if changes were made. The images or other third party material in this article are included in the article's Creative Commons licence, unless indicated otherwise in a credit line to the material. If material is not included in the article's Creative Commons licence and your intended use is not permitted by statutory regulation or exceeds the permitted use, you will need to obtain permission directly from the copyright holder. To view a copy of this licence, visit http://creativecommons.org/licenses/by/4.0/.

Publisher's Note Springer Nature remains neutral with regard to jurisdictional claims in published maps and institutional affiliations.
The original article can be found online at https://doi.org/10.1007/ s12328-021-01567-4.

Tomo Shimizu

tomo_shimizu@sekisui.com

1 Tsukuba Research Institute Research and Development Division, Sekisui Medical Co., Ltd., 3-3-1, Koyodai, Ryugasaki, Ibaraki 301-0852, Japan

2 Department of Molecular Gastroenterology and Hepatology, Graduate School of Medical Science, Kyoto Prefectural University of Medicine, Kyoto 602-8566, Japan

3 Department of Hepatology, Sapporo Kosei General Hospital, Hokkaido 060-0033, Japan

4 Laboratory of Molecular Biomedicine for Pathogenesis, Center for Disease Biology and Integrative Medicine, Faculty of Medicine, The University of Tokyo, Tokyo 113-0033, Japan
5 LEAP, Japan Agency for Medical Research and Development, Tokyo 113-0033, Japan

6 Laboratoire d'ImmunoRhumatologie Moléculaire, Plateforme GENOMAX, Institut National de la Santé et de la Recherche Médicale UMR_S 1109, Faculté de Médecine, Fédération Hospitalo-Universitaire OMICARE, Fédération de Médecine Translationnelle de Strasbourg, Laboratory of Excellence TRANSPLANTEX, Université de Strasbourg, Strasbourg, France

7 The Institute for AIM Medicine, Tokyo 101-0047, Japan

8 Department of Gastroenterology and Hepatology, Saiseikai Suita Hospital, Osaka 564-0013, Japan 